\title{
Clinical study of Duogastrone in the treatment of duodenal ulcers
}

\author{
B. O. AMURE \\ From the University of Ibadan, Nigeria
}

SUMMARY This study confirms the preliminary reports that Duogastrone effectively controls the symptoms of duodenal ulceration and appears to hasten healing. In a double-blind trial, 14 patients with active duodenal ulcers were treated with Duogastrone capsules, one four times daily, half-an-hour before meals, while a comparable control group of 14 patients was treated similarly with a placebo containing magnesium trisilicate. Treatment continued for 12 weeks with clinical assessments fortnightly and a radiological assessment at the start and at the end of treatment.

Only one of the 14 patients receiving Duogastrone did not respond. The remaining 13 showed marked clinical improvement with complete relief of pain and ceased to require supplementary antacids. Radiological evidence of healing or marked improvement was seen in eight of the 14 patients.

None of the patients in the control group showed any marked improvement either of pain or tenderness and no changes were detectable by radiology. Patients in this group showed no reduction in their demand for supplementary antacids to relieve symptoms. No significant side effects were encountered.

It is concluded that Duogastrone accelerates the healing of duodenal ulcer in ambulant patients and affords a much greater and more rapid relief of symptoms than does magnesium trisilicate.

Many investigations have confirmed the value of carbenoxolone sodium tablets (Biogastrone) in the treatment of gastric ulcer in ambulant patients. The rate of healing in these trials has been comparable with bed rest in hospital. The tablets, however, have not been shown to have a therapeutic effect in duodenal ulceration. probably because carbenoxolone is rapidly absorbed from the stomach. The precise mode of action of the drug is not known but there is evidence that its effect is topical rather than systemic.

A special positioned-release capsule (Duogastrone) has been designed which releases $50 \mathrm{mg}$ carbenoxolone sodium directly into the duodenum in a concentrated form and preliminary studies by Craig, Hunt, Kimerling, and Parke (1967), Hunt (1968), Lawrence, Manton, Mendl, and Montgomery (1968), and Cliff (1968) appeared 


\begin{tabular}{|c|c|c|c|c|c|}
\hline \multicolumn{3}{|c|}{ Duogastrone Group } & \multicolumn{3}{|c|}{ Control Group } \\
\hline $\operatorname{Sex}$ & Age & $\begin{array}{l}\text { History } \\
\text { (Years) }\end{array}$ & $\operatorname{Sex}$ & Age & $\begin{array}{l}\text { History } \\
\text { (Years) }\end{array}$ \\
\hline $\mathbf{M}$ & 20 & 10 & $\mathbf{M}$ & 30 & 7 \\
\hline $\mathbf{M}$ & 51 & 12 & $\mathbf{M}$ & 28 & $1 \frac{1}{2}$ \\
\hline $\mathbf{M}$ & 68 & 12 & M & 33 & 8 \\
\hline $\mathbf{F}$ & 38 & 4 & $\mathbf{M}$ & 41 & 2 \\
\hline $\mathbf{F}$ & 41 & 2 & $\mathbf{M}$ & 22 & 4 \\
\hline $\mathbf{M}$ & - & 10 & $\mathbf{F}$ & 26 & 2 \\
\hline $\mathbf{M}$ & 36 & 6 & $\mathbf{M}$ & 40 & $\frac{1}{4}$ \\
\hline $\mathbf{M}$ & 38 & 5 & $\mathbf{F}$ & 38 & 10 \\
\hline $\mathbf{M}$ & 24 & 4 & $\mathbf{M}$ & 28 & 6 \\
\hline $\mathbf{F}$ & 29 & 1 & $\mathbf{M}$ & 26 & 2 \\
\hline $\mathbf{M}$ & 47 & 10 & $\mathbf{M}$ & 23 & $\frac{1}{3}$ \\
\hline $\mathbf{F}$ & 38 & $\frac{1}{4}$ & $\mathbf{F}$ & 30 & Many years ${ }^{1}$ \\
\hline $\mathbf{F}$ & 39 & $\frac{1}{2}$ & $\mathbf{M}$ & 22 & 1 \\
\hline $\mathbf{M}$ & 42 & 1 & $\mathbf{F}$ & 19 & 1 \\
\hline Mean & $39 \cdot 4$ & $5 \cdot 6$ & & $29 \cdot 0$ & $3 \cdot 5$ \\
\hline
\end{tabular}

Table I Distribution of the patients

${ }^{1}$ These figures were omitted in calculation of the mean.

to demonstrate that this formulation exerted a pronounced healing effect upon duodenal ulcers.

\section{Materials and Methods}

A total of 28 patients were admitted to the trial. Criteria for admission were active symptoms of at least three months' duration plus an abnormal appearance of the duodenal cap after radiological examination. Patients with recent haemorrhage or perforation, or with stenosis, were excluded, as were those with cardiac or renal disease. There was no limitation by either age or sex.

All patients who met these requirements were admitted and the final group of 28 comprised 19 males and nine females (a ratio of about 2 to 1 ), whose ages ranged from 19 to 68 years. All social classes were represented. Details of distribution into Duogastrone or control groups, by age and duration of history, are given in Table I. It will be seen that there is a wide range of age and history in each group, but the patients in the Duogastrone group were, on average, some 10 years older and had significantly longer histories.

At the outset of the trial patients were assessed both clinically and radiologically. Treatment continued for 12 weeks, the patients being assessed clinically at fortnightly intervals and radiologically on completion of the course. Haematological examinations, including $\mathrm{Hb}$ estimations and MCHC determinations were made.

Patients were allocated to treatment with Duogastrone or placebo at random and received a fortnight's supply of tablets from the pharmacist at each visit. They were instructed to take them four times daily at 8 am, 12 noon, $6 \mathrm{pm}$, and $10 \mathrm{pm}$, half-an-hour before food. Neither the patient nor the examining physician knew $\stackrel{\overbrace{}}{\rightleftharpoons}$ whether this was a Duogastrone capsule or $\vec{\Rightarrow}$ a placebo containing magnesium trisilicate. All patients were also given supplies of tablets mag. trisil. co. to be taken as necessary to relieve symptoms and the number of these tablets consumed was recorded at each visit.

All patients were ambulant and followed their के normal occupations. They were advised to avoid $\vec{\circ}$ spicy foods but otherwise eat their normal diet. They were advised to restrict smoking to one or two cigarettes daily and to take no alcohol.

At each visit pain was scored as nil (1), moderate (2) or severe (3); tenderness was recorded as mild (1), moderate (2), or marked (3) and the number of additional alkali tablets taken each week was noted.

Radiological assessment was made at the start and at the end of treatment. No attempt was made to measure the size of any ulcer crater seen, but the general appearance in terms of presence of a crater, cap deformity, oedema, and spasticity was assessed as 'healed', 'improved', 'unchanged', or 'worse'.

\section{Results}

A comparison of the pain and tenderness scores is given in Table II, while the consumption of supplementary antacid tablets is shown in Table III. The final assessment both radiological and clinical, after 12 weeks of therapy, is summarized in Table IV.

\section{CLINICAL RESPONSE}

All patients but one presented with severe pain and marked tenderness upon admisson to the trial. The one exception suffered only moderate pain and tenderness on admission. He was allocated to the Duogastrone group and although his symptoms showed no obvious improvement he had stopped taking alkalis by the end of the trial.

Of the control group, half showed some relief of pain by the end of two weeks and two-thirds were showing some relief of tenderness by the end of six weeks, but none showed marked relief of pain or tenderness by the end of 12 weeks.

In the Duogastrone group, 10 out of 14 showed improvement in both pain and tenderness by the end of two weeks; by the end of six weeks none had severe pain or tenderness and by the end of 12 weeks only one of the 14 patients showed persistent symptoms.

\section{Antacid consumption}

The superior symptomatic response to Duogastrone is also reflected in the consumption of antacids. As Table III shows, the mean consumption of additional alkali tablets by the Duogas- 


\begin{tabular}{|c|c|c|c|c|c|c|c|c|c|c|c|c|}
\hline \multirow[b]{2}{*}{ Scores } & \multicolumn{3}{|c|}{$\begin{array}{l}\text { Week } \\
\text { Zero }\end{array}$} & \multicolumn{3}{|c|}{ Two } & \multicolumn{3}{|c|}{ Six } & \multicolumn{3}{|l|}{12} \\
\hline & 1 & 2 & 3 & 1 & 2 & 3 & 1. & 2 & 3 & 1 & 2 & 3 \\
\hline \multicolumn{13}{|l|}{ Pain } \\
\hline Control group & 0 & $\mathbf{0}$ & 14 & 1 & 6 & 7 & 1 & 9 & 4 & 0 & 12 & 3 \\
\hline Duogastrone group & 0 & 1 & 13 & 1 & 11 & 2 & 12 & 2 & 0 & 13 & 1 & 0 \\
\hline \multicolumn{13}{|l|}{ Tenderness } \\
\hline Control group & $\mathbf{0}$ & 1 & 13 & $\mathbf{0}$ & 4 & 10 & 0 & 9 & 5 & 0 & 5 & 9 \\
\hline Duogastrone group & $\mathbf{0}$ & 1 & 13 & 1 & 11 & 2 & 11 & 3 & $\mathbf{0}$ & 13 & 1 & 0 \\
\hline
\end{tabular}

Table II Pain and tenderness scores ${ }^{1}$

Pain score 1-nil 2-moderate 3-severe

Tenderness score 1-nil 2-moderate 3-marked

\begin{tabular}{|c|c|c|c|c|c|c|c|c|c|}
\hline \multirow[t]{3}{*}{ Antacid } & \multicolumn{3}{|l|}{ Weér } & & & & & & \\
\hline & \multicolumn{3}{|l|}{ Two } & \multicolumn{3}{|l|}{ Six } & \multicolumn{3}{|l|}{12} \\
\hline & Total & $\begin{array}{l}\text { No. } \\
\text { Taking }\end{array}$ & $\begin{array}{l}\text { Overall } \\
\text { Mean }\end{array}$ & Total & $\begin{array}{l}\text { No. } \\
\text { Taking }\end{array}$ & $\begin{array}{l}\text { Overall } \\
\text { Mean }\end{array}$ & Total & $\begin{array}{l}\text { No. } \\
\text { Taking }\end{array}$ & $\begin{array}{l}\text { Overall } \\
\text { Mean }\end{array}$ \\
\hline $\begin{array}{l}\text { Control group } \\
\text { Duogastrone group }\end{array}$ & $\begin{array}{r}218 \\
53\end{array}$ & $\begin{array}{l}14 \\
10\end{array}$ & $\begin{array}{r}15 \cdot 6 \\
3 \cdot 8\end{array}$ & $\begin{array}{r}214 \\
14\end{array}$ & $\begin{array}{r}14 \\
3\end{array}$ & $\begin{array}{r}15 \cdot 3 \\
1 \cdot 0\end{array}$ & $\begin{array}{r}211 \\
0\end{array}$ & $\begin{array}{r}14 \\
0\end{array}$ & $\begin{array}{c}15 \cdot 1 \\
0\end{array}$ \\
\hline
\end{tabular}

Table III Antacid consumption

\begin{tabular}{lllll}
\hline Radiological Changes & Healed & Improved & No Change & Worse \\
\hline Control group & 0 & 0 & 14 & 0 \\
Duogastrone group & 4 & 4 & 6 & 0 \\
Final Comments & Marked Improvement & & Little or no Change & Worse \\
Control group & 0 & & 14 & 0 \\
Duogastrone Group & 13 & 1 & 0 \\
\hline
\end{tabular}

Table IV Radiological and clinical assessment at 12 weeks

trone group fell from 3.8 per week by the end of the second week, to one per week after six weeks, and by the end of the trial no patient on Duogastrone was taking supplementary antacids. In the control group, by contrast, the mean consumption of antacid tablets remained virtually unchanged at slightly more than 15 tablets per person per week throughout the period of the trial.

\section{Radiological assessment}

The radiologist who assessed the patients before and after treatment was, like the physicians, unaware of which drug the patient had taken. The final assessment of the Duogastrone group showed apparent healing or marked improvement in eight out of 14 patients. No patient in the control group showed any significant change.
One patient on Duogastrone complained of nausea but continued with treatment: no other side effects were reported and in particular there was no sign of fluid retention or oedema. In the control group there was some frequency and looseness of bowel movement associated with large intake of magnesium trisilicate.

\section{Discussion}

Duodenal ulcer is a major medical problem in Nigeria and other paits of Africa, as it is in Europe, but its management is perhaps more difficult here than in more highly developed countries. Despite the great strides which have already been made in Nigeria in the provision of improved medical services, there are still comparatively few doctors available, and the population in general does not consult a physi- 
cian on account of minor symptoms. It is therefore possible that the physician in Africa encounters a selection of the more difficult cases of duodenal ulceration (as of other diseases) and that the spontaneous remission so frequently seen in Europe will be met less frequently in Nigeria. This suggestion is perhaps strengthened by the poor response of the control group in this study. It is certainly my impression at Ibadan that the medical treatment of outpatients is far from satisfactory, while hospital facilities are too limited to allow the free employment of inpatient medical treatment or surgery.

The results of this present study are therefore of particular interest in establishing that Duogastrone provides an effective outpatient treatment for duodenal ulcer. It certainly relieves symptoms both rapidly and completely, and it appears in many cases to encourage healing as observed radiologically.

The results are comparable with previous reports on Duogastrone. Craig et al (1967) similarly obtained complete symptomatic relief, and radiological evidence of healing, in 13 out of 15 patients treated, while only four out of 19 patients given dummy capsules containing lactose improved comparably. In that study treatment continued for only one month. In this trial, response to treatment was less rapid, though equally complete, but the control group showed much less improvement despite being allowed antacids ad libitum. This may imply what has already been suggested, that the patients tend to present with more severe ulceration.

Cliff (1968) treated 19 patients with Duogastrone for six weeks or 12 weeks as required, while a control group of 19 received an anticholinergic, propantheline bromide. At follow-up three to six months later, 14 of the Duogastrone group were free of symptom, compared with eight out of the control group.

Montgomery, Lawrence, Manton, Mendl, and Rowe (1968), who treated 22 patients with Duogastrone and 22 with antacids, found that after six weeks' treatment 13 of the Duogastrone group and eight controls were clinically 'healed', but after a further six weeks at half dosage or none this advantage was not maintained. Here again, the control group responded much better than in the present trial. Radiological examination at 12 weeks showed nine Duogastrone patients and three controls healed or improved.

A valid comparison can only be made of like with like, and the effect of Duogastrone on duodenal ulcer as it presents in Nigeria can only be judged fairly by means of a properly controlled study such as has been conducted. Nevertheless, the similarity between the results and those of other investigators in England does suggest strongly that, striking as the results are, they are most unlikely to be due to chance.
How Duogastrone exerts its healing effect is not yet fully understood, but the therapeutic effect of carbenoxolone sodium is believed to be topical rather than systemic. When swallowed as a tablet it has been shown to heal gastric ulcers, but appears to have little effect on ulcers in the mouth or duodenum. An oral gel containing carbenoxolone ('Bioral') has been reported by Jones (1965), Hunt (1965), Fowler (1967), Samuel (1967), and Simpson (1967) to accelerate healing of aphthous ulcers and other oral lesions. The Duogastrone capsule is the first preparation containing carbenoxolone sodium which has been shown to have any recognizable effect upon duodenal ulcer, and it has been shown by Galloway (1968) and Craig et al (1967) to release its content of carbenoxolone sodium directly into the duodenum.

In the stomach, carbenoxolone sodium has been shown by Goodier (1968) and by Johnson (1968) to increase the production of an adherent mucus, which may reinforce the epithelial defences. Owing to the difficulties of exploring the duodenum it cannot yet be said whether a similar effect is exerted there, but it is not impossible. Also the possibility cannot be discounted that the drug may in some way promote epithelial regeneration.

How this drug will affect the long-term prognosis of duodenal ulcer is uncertain. A long-term, multicentre trial is at present in progress in England. Montgomery's work (1968) with both Duogastrone and Biogastrone (Montgomery, Mehta, and Lawrence, 1969) suggests that both duodenal and gastric ulcers are just as liable to relapse whether they are healed with carbenoxolone or by other methods. Cliff (1968) suggests that relapse may be less likely in the short term if treatment with Duogastrone is continued for 12 weeks rather than for six weeks only. For this reason a 12-week treatment was chosen, and the progress of the treated group will be observed with interest.

But even if relapse does occur in a proportion of patients, both Hunt (1968) and Montgomery et al (1969) have noted that these patients will generally response to a second course of therapy with carbenoxolone. It must not be discounted that there is available a treatment which will reliably heal duodenalulcersin ambulant patients, without recourse to expensive and overloaded hospital facilities.

References

Cliff, J. M. (1968). A trial of carbenoxolone capsules in the Royal Navy. In Symposium on Carbenoxolone Sodium, edited by J. M. Robson and F. M. Sullivan, pp. 239-244. Butterworth, London.

Craig, O., Hunt, T., Kimerling, J. J., and Parke, D. V. (1967). Carbenoxolone in the treatment of duodenal ulcer. Practitioner, 199, 109-111.

Fowler, P. B. S. (1967). Notes and Queries-Aphthous ulceration in the mouth. Practitioner, 199, 253-254.

Galloway, R. (1968). Development of the Duogastrone capsule. In Symposium on Carbenoxolone Sodium, edited by J. M. Robson and F. M. Sullivan, pp. 203-208. Butterworth London. 
Goodier, T. E. W. (1968). Histopathology of gastric ulcers treated with carbenoxolone. In Symposium on Carbenoxolone Sodium, edited by J. M. Robson and F. M. Sullivan, pp. 111-126. Butterworth, London.

Hunt, T. C. (1968). Clinical experience with carbenoxolone capsules ('Duogastrone') in duodenal ulcer. In Symposium on Carbenoxolone Sodium, edited by J. M. Robson and F. M. Sullivan, pp. 195-201. Butterworth, London.

Hunt, T. C. (1965). Carbenoxolone sodium in the treatment of peptic ulcer. Med. Dig. (Lond.), 10, 222-224.

Johnson, F. R. (1968). The cytological approach to the evaluation of drug action on gastric mucosa. In Symposium on Carbenoxolone Sodium, edited by J. M. Robson and F. M. Sullivan, pp. 93-109. Butterworth, London.

Jones, F. (1965). Current therapeutics: CCXV. Carbenoxolone. Practitioner, 195, 698-700.

Lawrence, I. H., Manton, D. J., Mendl, K., and Montgomery, R. D. (1968). A three months assessment of Duogastrone therapy in chronic duodenal ulcer. In Symposium on Carbenoxolone Sodium, edited by J. M. Robson and F. M. Sullivan, pp. 217-223. Butterworth, London.

Montgomery, R. D., Lawrence, I. H., Manton, D. J., Mendl, K. and Rowe, P. (1968). A controlled trial of carbenoxolone sodium capsules in the treatment of duodenal ulcer. Gut, 9, 704-706.

Montgomery, R. D., Mehta, S. C., and Lawrence, I. H. (1969). Carbenoxolone in the long-term management of gastric ulcer. Practitioner, 202, 398-404.

Samuel, O. W. (1967). Periadenitis mucosa necrotica recurrens treated with topical carbenoxolone gel. Practitioner, 199, 220-222.

Simpson, P. M. (1967). Work in an oral surgery unit. Dent. Hlth, 6, 47-50. 